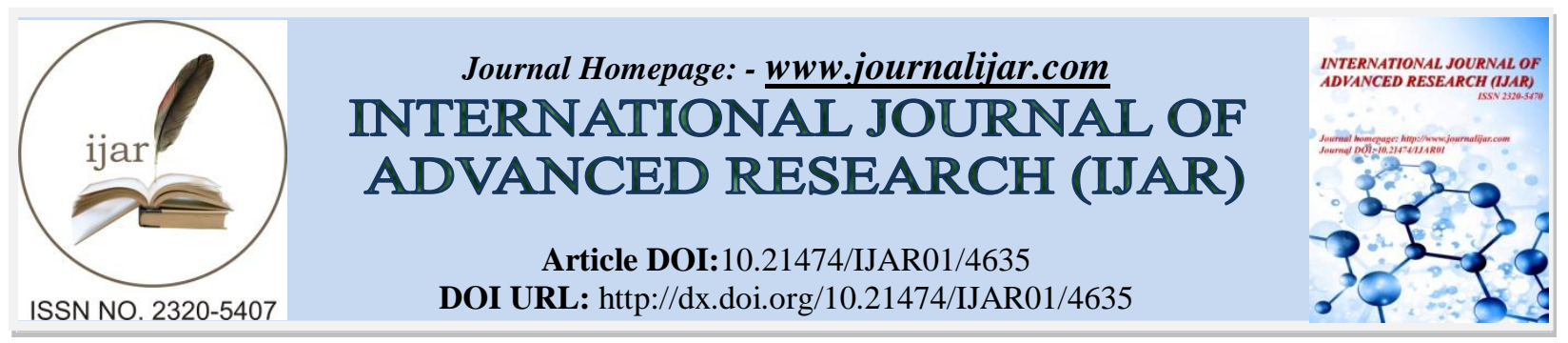

RESEARCH ARTICLE

\title{
EMPOWERING TRIBAL POPULATION THROUGH INDIAN INTELLECTUAL TRADITIONS OF
} VEDIC MATHEMATICS.

\section{Dr. Smitha S.}

Assistant Professor, SreeNarayana Training College, Nedunganda, Varkala, Thiruvananthapuram, Kerala.

\section{Manuscript Info}

Manuscript History

Received: 27 April 2017

Final Accepted: 29 May 2017

Published: June 2017

Key words:-

Empowerment, Tribal population, Vedic Mathematics

\section{Abstract}

Education has been treated as a fundamental human right enshrined in the Universal Declaration of Human Rights and the International Human Rights Covenants, achieving the rights for the basic education, particularly for the underprivileged sections of the society is not only the obligation of the State, but the biggest moral challenge. It is well known that a rapid growth in educational attainment is the most successful medium for social empowerment of the disadvantaged ST \& SC members. The present paper tries to empower the Tribal students by enhancing their Problem Solving Ability and Computational Speed and thereby the Self Confidence through the applications of Indian Intellectual traditions of Vedic Mathematics.

Copy Right, IJAR, 2017,. All rights reserved.

\section{Introduction:-}

The constitution of India, in Article 366, has defined the Scheduled Tribes as such of those tribes or tribal communities which have been so declared by the Constitution Order under Article 342 for the purpose of Constitution. There are 574 tribal groups who have been identified as Scheduled Tribe. Lack of education of tribes has inevitably linked it to their poor economic condition and poverty. As per the 2011-'12 census, ST students constitute 1.86\% of total enrolment in schools in the year 2011-12. The percentage of ST students in government schools, private aided schools and private unaided schools are 3.37\%, 1.33\% and 0.37\% respectively in 2011-12. The drop out ratio of ST students was $2.33 \%$. The pass percentage of SC students also increased from $50.80 \%$ to $60.46 \%$ and ST students from $41.16 \%$ to $52.31 \%$ during 2010-11. 2882 Scheduled Tribe students were enrolled for courses in arts and science colleges in 2010-11. The enrolment of ST students in degree and post graduate courses are 2528 and 354 respectively. Girls constitute 60\% of total ST students in Arts and Science colleges.

Tribes and their Education:-

"A tribe is a social group with territorial affiliation, endogamous, with no specialization of functions, ruled by tribal officers, hereditary or otherwise, united in language or dialect, recognizing social distance with other tribes or castes, without any social obloquy attaching to them, as it does in the caste structure, followed tribal traditions, beliefs and customs, illiberal of naturalization of ideas from alien sources, above all conscious of homogeneity of ethnic and territorial integration."(DN Majumdar quoted in Hasnain, 1998:4) In the education sector the literacy rate among tribes is very low and the majority children continue to be outside the school system. The Government introduced special educational support to the tribes. Special norms and flexible approaches introduced. But the number of the out of school children is large. Here also the number of enrollment among tribes is very low and the dropout rate is very high. There are number of reasons behind this, like lack of parental support and interest, inability to understand the medium of instruction due to mother to inhibition, lack of schools nearby, teacher 
absenteeism attitude towards girls etc. In formulating policies and programmes for tribal education it is essential to understand the complex realities of tribal life and the expectation of tribes from the system.

\section{Problems of Education of Tribal People:-}

Government planners see education as indispensable for helping tribal peoples cope with national integration. Education will also determine their prosperity, success and security in life. The tribes which remain either deprived of or negligent toward education will suffer the consequence. Government reports indicate that there is no scarcity of schools, other facilities or scholarships for the implementation of tribal education schemes. Even though the tribes are living away from so called civilized society, the globalized changes reflect in their life too not in a profitable way but in an undesirable mode. At present the indicators of socio- economic development is high in Kerala but it doesn't reflect in tribal life. Their life is in the transforming state losing their identity. There are a lot of issues that the tribal face today, it can be poor academic standard, sexual abuse, alcohol and drug addiction, violence etc. these all issues make them unable to apply their complete potential. These tribal youth often lacks a real role model from their community. The dropout rate of tribal students is high compared to other section students. Since the tribal children are rehabilitated to new system of learning it is very difficult for them to adapt the system of learning that our education system is following. They do have their own practical skills. But those skills are not sufficient for them when they face the reality in the society.

\section{Need for Empowerment:-}

Tribal students, even while they study at the secondary and college levels, should, be encouraged to come out with self-confidence. For that they should become aware and conscious of their innate capacities. Their hidden talents are to be nourished out. They should be well trained in the acquisition of various skills which are essential for selfsufficiency. Development in tribal societies should focus on educational programs that encourage keeping tribal youth genuinely integrated in their own culture. Empirical evidences (Dube, 1977; Sujatha, 1999) reveal that tribal children possess the basic cognitive abilities and psychological dispositions for successful participation in schools but there is no sufficient intrinsic and extrinsic motivation to achieve the academic goals. Sachidananda (1996) explained that lack of ambition and unfavorable attitude towards education were the main reasons for the failure of tribal children. It can be gratified that there is a slight increase in the field of tribal education as a result of implementing different new strategies by the government.

\section{Vedic Mathematics, A Suitable Strategy for Confidence Building:-}

Vedic Mathematics offers a new approach to resolving the current crisis in education (Puri\&Weinless, 1988; Puri, 1988).It is not simply a collection of new computational techniques; rather, it provides an entirely different approach to mathematical computation, based on pattern recognition (Puri, 1991). It has since been shown that the system is equally applicable to more up-to-date aspects of mathematics both at an elementary level as well as in more sophisticated fields (Nicholas, Williams, \& Pickles, 1984). The reason that this is possible relies on the nature of the sutras. They frequently describe how the mind approaches, or deals with, a problem in the earliest way (Puri\&Weinless, 1988). The Vedic system teaches this sort of approach systematically rather than leaving it to chance and hence we find a number of different possible methods for any particular sum. This is of tremendous use because it enhances variety of strategy. It also enables the subject to be kept alive by directing the attention towards underlying pattern and relationship (Stoddard, 1962; Starkey \&Gelman, 1982).It is a system with mental multi choice procedures, which keep the mind alert and agile. It is a complete and most natural Vedic System, which develop our brain to wonderful levels (Reyes, 1984). Puri points out that the naturalness and case of Vedic Sutra based computation "brings smiles on the face and joy in the heart" of the students which bring mental strength and confidence (Puri, 1986). Further, Vedic Mathematics reduces anxiety and increases playfulness.

This spark tempted the investigator to implement Vedic computational strategies in improving computational speed and problem solving ability of tribal students and thereby build up confidence upon them.

\section{Objectives of the study:-}

The study was conducted among a population of tribal children. The present study was undertaken with the following objectives:

1. To test the effectiveness of the Supreme power of Vedic Mathematics in enhancing Problem Solving Ability and Computational Speed of tribal children.

2. To equip the tribal children with self-confidence by attaining skills of Problem Solving Ability and Computational Speed through Indian intellectual tradition of Vedic Mathematics 


\section{Hypotheses of the study:-}

The following hypotheses were formulated by the investigator to lead the study

1. Vedic Mathematics applications are very much effective in enhancing Problem Solving Ability and Computational Speed of tribal children.

2. Acquisition of the skills of Vedic Mathematics applications is the true solution in equipping tribal children with self-confidence.

\section{Methodology:-}

Population and profile of the sample:-

In this study,the researcher made an attempt to enhance the Problem Solving Ability and Computational Speed of tribal children and thereby increase their Self-Confidence. The sample selected were 40 tribal students of Kerala with special reference to Kollam District. The samples were secondary school students selected using random sampling technique.

\section{Design, participants and procedure:-}

The design selected for the study was Pre-test Post-test Single group design. A package of select Vedic Sutras with 'EkadhikenaPurvena', EkanyunenaPurvena and UrdhavTiryagbhyam, pre-tested Problem Solving Ability Test, Computational speed test, and a Self -Esteem Scale prepared by National Center for Injury Prevention and Control were the tools. Before the intervention, a pre-test was conducted among the students. At the end, Post-Test was administered and the scores were collected. After an interval of 1 month, a retention test was given without any notice. The same tools were used for administering the retention test. Appropriate statistical technique like Repeated ANOVA, LSD test of post hoc comparison were used for testing the impact of Vedic sutras in attaining predetermined objectives and interpreted accordingly.

Data Analysis:-

Table 1:- Mean values and Standard Deviations of Problem Solving Ability scores in pre, post and retention tests of tribal students in experimental group

\begin{tabular}{|c|c|c|c|}
\hline Group & N & Mean & SD \\
\hline Pre Experimental & 40 & 7.21 & 2.59 \\
Post Experimental & 40 & 18.10 & 1.51 \\
Retention Experimental & 40 & 17.68 & 1.68 \\
\hline
\end{tabular}

Table 2:- Summary of Repeated ANOVA of Problem Solving Ability scores in pre, post and retention tests of tribal students in experimental group

\begin{tabular}{|c|c|c|c|c|c|}
\hline Group & Source of variation & Sum of Squares & df & Mean squares & F-ratio \\
\hline \multirow{3}{*}{ Experimental } & Between Groups & 9183.07 & 1 & 4591.54 & \\
& Between Subjects & 598.00 & 39 & & $1352.00^{* *}$ \\
& Error & 808.26 & 78 & 3.40 & \\
& Total & 10589.33 & 138 & & \\
\hline
\end{tabular}

**Significant at 0.01 level

Table 3:- Results of LSD Test for significance between pairs of mean scores of Problem solving ability of tribal students of the experimental group

\begin{tabular}{|c|c|c|c|}
\hline SI No & Pairs & Mean values & Mean Difference \\
\hline 1 & Pre-Experimental & 7.21 & $10.89^{* *}$ \\
\hline 2 & Post-Experimental & 18.10 & $10.47^{* *}$ \\
& Pre-Experimental & 7.21 & $0.42^{* *}$ \\
\hline 3 & Retention Experimental & 17.68 & \\
\hline
\end{tabular}

** Significant at 0.01 level 
Table 4:- Mean values and Standard Deviations of computational speed scores in pre, post and retention tests of tribal students in experimental group

\begin{tabular}{|c|c|c|c|}
\hline Group & N & Mean & SD \\
\hline Pre Experimental & 40 & 18.71 & 3.48 \\
Post Experimental & 40 & 9.10 & 0.88 \\
Retention Experimental & 40 & 9.80 & 0.18 \\
\hline
\end{tabular}

Table 5:- Summary of Repeated ANOVA of Computational Speed scores in pre, post and retention tests of tribal students in experimental group

\begin{tabular}{|c|c|c|c|c|c|}
\hline Group & Source of variation & $\begin{array}{c}\text { Sum of } \\
\text { Squares }\end{array}$ & df & $\begin{array}{c}\text { Mean } \\
\text { squares }\end{array}$ & F-ratio \\
\hline \multirow{3}{*}{ Experimental } & Between Groups & 6213.94 & 1 & 3106.97 & \\
& Between Subjects & 510.20 & 39 & & $716.95 * *$ \\
& Error & 1031.39 & 78 & 4.33 & \\
\hline
\end{tabular}

**Significant at 0.01 level

Table 6:- Results of LSD Test for significance between pairs of mean scores of Computational Speed Test of tribal students in experimental group

\begin{tabular}{|c|c|c|c|}
\hline Sl No & Pairs & Mean values & Mean Difference \\
\hline 1 & Pre-Experimental & 18.71 & $9.61 * *$ \\
& Post-Experimental & 9.10 & $8.91 * *$ \\
\hline 2 & Pre-Experimental & 18.71 & $0.70^{* *}$ \\
& Retention Experimental & 9.80 & \\
\hline \multirow{2}{*}{3} & Post-Experimental & 9.10 & \\
& Retention Experimental & 9.80 & \\
& & & \\
\end{tabular}

Table 7:- Result of Self Esteem Survey after Intervention

\begin{tabular}{|c|c|c|c|c|c|}
\hline Sr.No. & Items & $\begin{array}{l}\text { Strongly } \\
\text { Agree }\end{array}$ & $\begin{array}{c}\text { Agree } \\
\text { Somewhat }\end{array}$ & $\begin{array}{c}\text { Somewhat } \\
\text { Disagree }\end{array}$ & $\begin{array}{l}\text { Disagree } \\
\text { Strongly }\end{array}$ \\
\hline 1. & $\begin{array}{c}\text { I feel that I have a number of good } \\
\text { qualities. }\end{array}$ & 31 & 5 & 4 & - \\
\hline 2. & $\begin{array}{l}\text { I feel that I'm a person of worth, at least } \\
\text { on an equal par with others. }\end{array}$ & 32 & 6 & 2 & - \\
\hline 3. & $\begin{array}{l}\text { All in all, I am inclined to feel that I'm a } \\
\text { failure. }\end{array}$ & - & - & - & 40 \\
\hline 4. & $\begin{array}{l}\text { I am able to do things as well as most } \\
\text { other people. }\end{array}$ & 36 & 3 & 1 & - \\
\hline 5. & I feel I do not have much to be proud of. & - & - & 28 & 22 \\
\hline 6. & I take a positive attitude toward myself. & 34 & 4 & 2 & - \\
\hline 7. & On the whole, I am satisfied with myself. & 36 & 3 & 1 & - \\
\hline 8. & $\begin{array}{l}\text { I wish I could have more respect for } \\
\text { myself. }\end{array}$ & 24 & 12 & 2 & 2 \\
\hline 9. & I certainly feel useless at times. & - & - & - & 40 \\
\hline 10. & At times I think that I am no good at all. & - & - & 7 & 33 \\
\hline
\end{tabular}

Source: Centers for Disease Control and Prevention, National Center for Injury Prevention and Control. (2005). 
When the Pre-Intervention scores were analyzed, the self-esteem rating was very low (below 10). The result here shows that, after the intervention, the rate of self-perception on self-esteem has considerably enhanced which clearly reveals that Vedic Mathematics skill acquisition can enhance the confidence level of the learners.

\section{Discussion:-}

When the results of Analysis of Variance of post-test scores on Problem Solving Ability Test and Computational Speed Test of participants were taken, the difference between the means was found to be statistically significant ( $\mathrm{F}$ $(1,39)=1352.00 . ; \mathrm{p}<0.01)$ and $\left(\mathrm{F}_{(1,39)}=716.95 . ; \mathrm{p}<0.01\right)$. The result clearly gives the evidences that Vedic Sutras are very effective in enhancing Problem Solving Ability and Computational Speed among the sample of study. Research on the effects of Vedic Mathematics on improving Computational Speed includes the works by Nicholas, Williams \& Pickles (1984), Hope (1987), Muchlman (1994), and Haridas (2004) who concluded that "Vedic Mathematics provides very easy, one line, mental and superfast methods".

\section{Findings:-}

1. Vedic Mathematics applications are very much effective in enhancing Problem Solving Ability and Computational Speed of tribal children.

2. Acquisition of the skills of Vedic Mathematics applications is the true solution in equipping tribal children with self-confidence.

3. The continuous practice and application of Vedic One line method of computation indirectly empower the tribal student community in their overall personality development

To empower the children of tribal community, the study throws light on the suggestions that the

Regular motivation sessions with the Tribal students, Counseling to the needy children, Life orientation programmes, Leadership and personality development training programmes and Summer Camps focusing on over all development of the tribal children are to be conducted on a regular basis.

\section{Conclusion:-}

Each child including tribal-child has the right to free and compulsory education. Indian Constitution guarantees basic rights which are to be protected and promoted. Although the tribal department and Government of Kerala do a number of projects and programmes for the integral development of Tribal children, they face a number of problems with regard to education. They need to be addressed and tackled and thus the dreams of tribal children are fulfilled. It can be summarized that these people need special care and attention in academic part of life otherwise their holistic development is impossible which should not ever happen as our India, the nation which uphold the values of Dharma, the concept of 'Vasudhivakudumbakom' to be achieved even by uplifting the downtrodden.

\section{Acknowledgement:-}

This paper is the outcome of a Major Research Project sponsored and funded by Indian Council of Social Science Research. The author would like to thank for the support provided by ICSSR, Govt. of India and all members of the Project Team as well as the Advisory Committee members who contributed much for the fruitful result of the effort.

\section{References:-}

1. Annual report 2012-2013, Ministry of Tribal Affairs, New Delhi

2. Annual Report of Ministry of Tribal Affairs (2011), New Delhi,Ministry of Tribal Affairs

3. Bagai, SWetha. And Nundy,Neera,(2009), "Tribal Education a Fine Balance"Mumbai, Dasra Publications Chaudhari, Sarit K. and Chaudhari, SuchetaSen Mittal (2005) "Primitive Tribes in Contemporary IndiaConcepts, ethnography \& Demography (Vol - 1)" New Delhi, Mittal Publication.

4. Dube, S.C., (1990) "Indian Society", New Delhi, National Book Trust.

5. Dube,S.C., (1977) Tribal Heritage of India (Ed),Vol.1 , New Delhi,Vikas Publishing House. Madhava

6. KIRTADS Thakur,Devendra and Thakur,D.N., (1994) "Tribal Life and Forest", New Delhi Deep and Deep Publication

7. Menon,T.,(1996) “The Encylopaedia of Dravidian Tribes"vol 1, Thiruvananthapuram, The International School of Dravidian Linguistics.

8. Majumdar, D.N., (1973) "Races and Cultures of India", New Delhi, Asia Publishing House

9. NarayanaSwamy,Raju,(2010) The Challenges of Educating Scheduled Tribes In Kerala.I Indian Journal of Adult Education Vol 71,No.4. 
10. Puri, N. (1991). Ancient Vedic Mathematics: Correspondence courses. Roorkee, India:University of Roorkee Press.

11. Puri, N. \&Weinless, M. (1988). Vedic Mathematics: The cosmic software for the cosmic computer. Paper presented at the National Council of Teachers of Mathematics Annual Conference, Chicago, IL.

12. Sachchidananda and Prasad,R.R., (1996) "The Encylopaedia of Dravidian Tribes", Delhi, Discovery Publishing House.

13. Singh,K.S., "Concept of Tribe; a Note"(2006)Saksena,H.S.,SrivasthavaVinay Kumar and ChaudariSukantha K. "Scheduled Tribe and development", Delhi,Serial Publication.

14. State Planning Board Report-Chapter12 Education.

15. Sujatha,K. (1999), "Education of India Scheduled Tribes:A study of Community Schools in the District of Vishakhapattanam,andrapradesh",Delacroix,UNESCO Publication.

16. SukumaranNair,P.K. (2003) "Scheduled Tribe at a Glance", Kozhikkode,

17. Tirtha, S.B.K. (1965). Vedic mathematics. Delhi, India: MotilalBanarsidass

18. Williams, K.R. (1984). Discover Vedic mathematics: A practical system based on sixteen simple formulae. Available through Vedic Mathematics Research Group, Roorkee University, Roorkee 247667 , India.

19. https://www.culturalsurvival.org/publications/cultural-survival-quarterly/tribal-education-india

20. www.cdit.org www.stdd.kerala.gov.in

21. [ Self-esteem Survey] Source: Centers for Disease Control and Prevention, National Center for Injury Prevention and Control. (2005). Violence-Related Attitudes, Behaviors, and Influences Among Youths: A Compendium of Assessment Tools, 2nd ed. Atlanta, GA: Dahlberg LL, Toal SB, Swahn M, Behrens CB. Electronic version available: http://www.cdc.gov/ncipc/pub-res/measure.htm. 